Article

\title{
High-Resolution Imagery of Earth at Night: New Sources, Opportunities and Challenges
}

\author{
Christopher C. M. Kyba ${ }^{1,2,3, *}$, Stefanie Garz ${ }^{3}$, Helga Kuechly ${ }^{1}$, Alejandro Sánchez de Miguel ${ }^{4}$, \\ Jaime Zamorano ${ }^{4}$, Jürgen Fischer ${ }^{3}$ and Franz Hölker ${ }^{1}$ \\ ${ }^{1}$ Leibniz Institute of Freshwater Ecology and Inland Fisheries, Müggelseedamm 310, 12587 Berlin, \\ Germany; E-Mails: helga.kuechly@gmail.com (H.K.); hoelker@igb-berlin.de (F.H.) \\ 2 Deutsches GeoForschungsZentrum Potsdam, Telegrafenberg, 14473 Potsdam, Germany \\ ${ }^{3}$ Institute for Space Sciences, Freie Universität Berlin, Carl-Heinrich-Becker Weg 6-10, 12165 Berlin, \\ Germany; E-Mails: stefanie.garz@yahoo.com (S.G.); juergen.fischer@wew.fu-berlin.de (J.F.) \\ ${ }^{4}$ Dept. Astrofísica y CC. de la Atmósfera, Universidad Complutense de Madrid, Avda. Complutense \\ s/n, Madrid 28040, Spain; E-Mails: alejandrosanchezmiguel@ fis.ucm.es (A.S.M.); \\ jzamorano@fis.ucm.es (J.Z.) \\ * Author to whom correspondence should be addressed; E-Mail: kyba @ gfz-potsdam.de; \\ Tel.: +49-331-288-28973.
}

Academic Editors: Christopher D. Elvidge and Prasad S. Thenkabail

Received: 12 September 2014 / Accepted: 15 December 2014 / Published: 23 December 2014

\begin{abstract}
Images of the Earth at night are an exceptional source of human geographical data, because artificial light highlights human activity in a way that daytime scenes do not. The quality of such imagery dramatically improved in 2012 with two new spaceborne detectors. The higher resolution and precision of the data considerably expands the scope of possible applications. In this paper, we introduce the two new data sources and discuss their potential limitations using three case studies. Data from the Visible Infrared Imaging Radiometer Suite Day-Night Band (VIIRS DNB) is shown to have sufficient resolution to identify major sources of waste light, such as airports, and we find considerable variation in the peak radiance of the world's largest airports. Nighttime imagery brings "cultural footprints" to light: DNB data reveals that American cities emit many times more light per capita than German cities and that cities in the former East of Germany emit more light per capita than those in the former West. Photographs from the International Space Station, the second new source of imagery, provide some limited spectral information, as well as street-level resolution. These images may be of greater use for epidemiological studies than the lower resolution DNB data.
\end{abstract}


Keywords: artificial light; energy; international space station; light pollution; night; remote sensing; visible band

\section{Introduction}

Artificial light at night is one of the clearest indicators of human activity available via remote sensing. Images of the Earth at night are therefore an extremely useful tool for research involving human communities and their interaction with the environment. Night light data have been used in the past to study economic variables [1,2], socio-economic properties [3-5], population [6,7] and population density [8], built area [9,10], power consumption [11], greenhouse gas emissions [12], gas flaring [13], atmospheric chemistry [14], skyglow (light pollution) [15-17], the epidemiology of illness related to light exposure [18], among other analyses [19].

In 2012, there was a dramatic change in the quality of available nighttime Earth observation data. The new data has greatly improved resolution, accuracy and sensitivity, and the scope of possible applications is therefore likely to increase. The purpose of this paper is to alert researchers to these new data sources and to promote their use. The data sources are highlighted in three case studies that examine patterns of light use and energy consumption. The limitations of the data are discussed within the case studies themselves and summarized in the results and discussion. All of the night light data analyzed in this paper are freely available online.

\subsection{Data Sources}

Nearly all of the analyses of night light data thus far have been based on measurements from the Defense Meteorological Satellite Program-Operational Linescan System (DMSP). In 2012 a new instrument flown on the Suomi National Polar-orbiting Partnership satellite became operational. The Visible Infrared Imaging Radiometer Suite Day-Night Band (VIIRS DNB) images the entire Earth nightly at a resolution of about 750 meters. The VIIRS DNB has 45-88-times better spatial resolution than DMSP, and 14-bit compared to 6-bit digitization [20]. Suomi NPP orbits the Earth 14 times per day on a 16-day repeat cycle. The average time at which images are taken is near 01:30 in local solar time, but can vary by over an hour depending on latitude and the particular cycle. Because the overpass time is near midnight, high latitude sites are imaged during night for a greater portion of the year than was possible with DMSP, which had a 19:30 overpass time.

Global data products based on VIIRS DNB are produced by the Earth Observation Group of the National Oceanic and Atmospheric Administration. While data from individual passes of the satellite are available, most researchers are likely to prefer using "cloud-free composite" images that are based on many passes of the sensor over the target on cloud-free moonless nights. Instead of having 750-meter resolution, cloud-free composite data are binned into a 15 -arcsecond grid spanning from 65 south to 75 north latitude. The pixel size therefore depends on the latitude. The background from atmospheric airglow emission is faint compared to city lights and is not yet subtracted [21]. Cloud-free composite images are currently available at http://ngdc.noaa.gov/eog/download.html. As of the moment of writing, 
DNB "stable light products" with transient sources removed (e.g., aurora, fires, fishing boats) have not yet been published. A detailed description of DNB is presented in [20].

The second new data source is astronaut photographs of the Earth at night. Astronauts have been taking such images for years, but the quality greatly improved with the installation of the NightPod instrument in 2012. All photographs taken from the International Space Station are available at "The Gateway to Astronaut Photography of Earth", which is run by NASA: http://eol.jsc.nasa.gov. Finding a nighttime image of a specific city among the millions of images is, however, a difficult task. The "Atlas of astronaut photos of Earth at night" was developed to solve this problem. The Atlas provides an open directory of geotagged images of cities at night, with links to the original images at the NASA site [22]. The main page of the Atlas is at http://www.citiesatnight.org/, and access to the database itself is available at http://www.nightcitiesiss.org/. The original Atlas was put together by experts, but its future expansion will mainly come through a related citizen science portal for classifying and georeferencing ISS images [23]. A tutorial on how to use the Atlas database is available at http://tinyurl.com/qfolkq6.
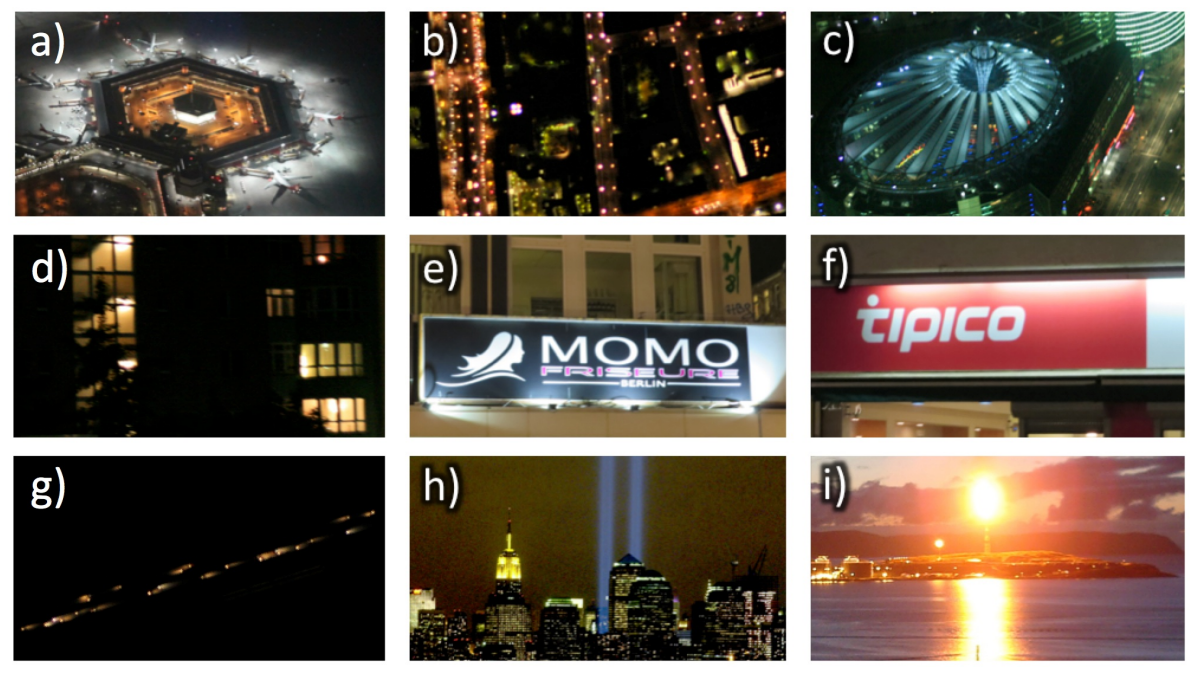

Figure 1. Some important sources of light at night. (a) Area lighting with no direct uplight; (b) area lighting including direct uplight; (c) architectural lighting; (d) lit windows; (e) illuminated sign with direct uplight emission; (f) illuminated sign with no direct uplight; (g) auto headlights; (h) searchlight; (i) gas flare. (a-g) by C Kyba; (h) "Tribute in Light" by Mike Hvozda, from Wikimedia Commons; (i) "Hammerfest dusk LNG" by Andreas Rümpel, from Wikimedia Commons.

\subsection{Sources of Light}

Many different light are responsible for the light that shines into space. In an aerial survey, Kuechly et al. performed the first large-scale investigation of the sources of light observed by nadir-viewing satellites [9]. Their study of Berlin found that the most important areas emitting light toward the zenith were streets, responsible for $32 \%$ of the detected light. Other important regions were industrial areas (16\%), public service areas (10\%), block buildings (8\%), city center (6\%), airfields (4\%) and supply and disposal facilities (4\%). 
Figure 1 shows examples of some common sources of light at night. Light sources have different angular emission profiles, and the light viewed by a satellite may include light shining directly from a source and light scattered by the ground or buildings. Tall buildings and vegetation can also block a view of the street level. It is important that this be considered when using such data for analyses, like understanding energy consumption or sources of skyglow. In fact, beamed or horizontal sources of light that are readily visible from the ground and contribute to energy use and skyglow may be nearly invisible to a nadir viewing instrument (e.g., Figure 1d,f,g,h).

\section{Experimental Section}

\subsection{Case Study 1: Differences in City Lighting at Small Spatial Scales}

The first case study examines the variation in how cities are lit at the street level, particularly regarding color and brightness. Two series of astronaut photographs from the International Space Station are compared. The first set was chosen because all six photos were taken on the same night; the second set considers a city that has been photographed many times on different nights.

\subsubsection{Background}

As a shirt-sleeve environment, the International Space Station allows remote sensing of Earth with standard commercial cameras and lenses. High-resolution nighttime imagery is possible by compensating for the motion of the ISS over the Earth [24]. The European Space Agency NightPod system (installed in 2012) has provided imagery with resolutions better than 10 meters. The cameras currently in use provide image information in three spectral bands in the visual range (red, green and blue).

The limitations of the technique are related to the station itself. The station orbit restricts it to latitudes less than $51.6^{\circ}$ from the equator and some large cities are outside of this range. To reduce atmospheric effects, the ideal viewing geometry is near-nadir. Taken together with the low orbital altitude, this limits the frequency with which any given city can be imaged. The flyover times of the ISS are not consistent, which can be either an advantage or disadvantage, depending on the application. The cameras take images through the ISS windows, and this introduces an unknown attenuation factor. Radiance calibration of the camera/lens/window system could be obtained via stellar photometry [25,26]. The windows potentially set a limit on the best possible image resolution and prevent imaging when the Sun shines on the window.

\subsubsection{Dataset}

Composite images were produced from two series of photographs from the ISS. Figure 2 shows images of six European cities from the night of 11-12 February 2012, when a large portion of the continent was cloud free. The photos were taken with the same model of camera (Nikon D3S) and lens (AF Nikkor $180 \mathrm{~mm}$ f/2.8D IF-ED), with identical settings (ISO 6400, $20 \mathrm{~ms}, \mathrm{f} / 2.8$ ) and with a near-nadir view in each case. The images were taken during three passes of the ISS, and were therefore 
not all photographed at similar local times. The original high-resolution photos are available at the NASA Gateway to Astronaut Photography (Table 1, including population figures from [27]).

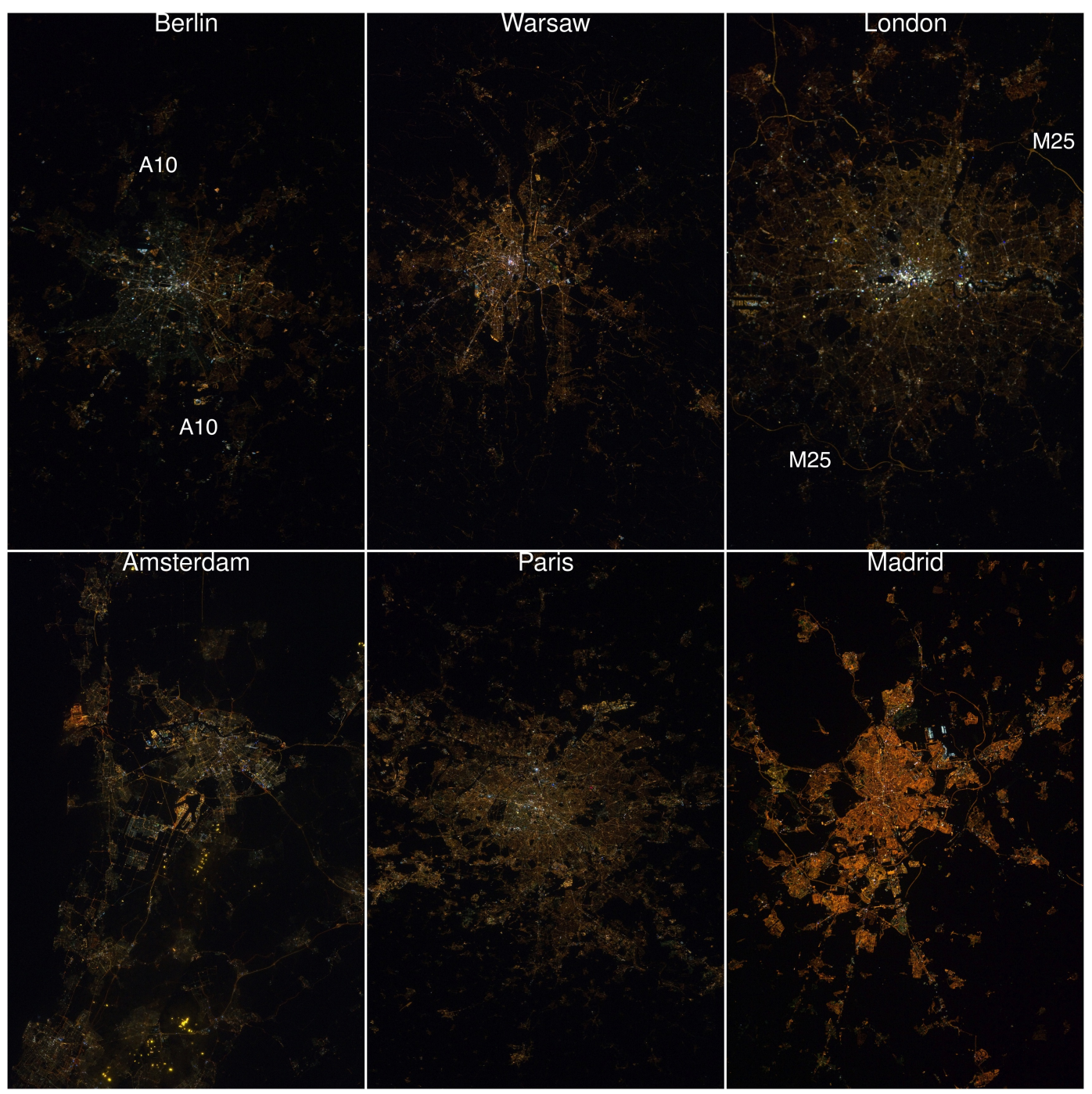

Figure 2. Nighttime images of six European cities. Identical camera settings were used for each photograph. The M25 motorway around London is visible, but the A10 Autobahn ring around Berlin is not visible. Images courtesy of the Earth Science and Remote Sensing Unit, NASA Johnson Space Center.

Figure 3 is from [28] and shows nine images of Madrid, Spain, taken at different times of the night on different days over a period of 2.3 years (Table 2). Different camera and lens combinations were used to take the photographs. The raw image data were processed to convert each image to an equivalent exposure using differential photometry and will be described in detail in a forthcoming paper. In brief, the radiance scale is set by matching the brightness of two large and approximately uniformly lit water treatment plants with no nearby buildings on the outskirts of the city $\left(40.300492^{\circ} \mathrm{N}, 3.603441^{\circ} \mathrm{W}\right.$ and $40.292962^{\circ} \mathrm{N}, 3.886355^{\circ} \mathrm{W}$ ). These areas were chosen because of their size and because light emitted at large angles is not blocked by buildings. 
Table 1. Images used in the six city composite. (*) Local time in London is one hour earlier than the other five cities; the photo was taken one minute before the photo of Amsterdam. $(* *)$ The image of Madrid was taken with a different Nikon D3S than the other five images.

\begin{tabular}{cccc}
\hline City & Population (Millions) & Image Name & Local Time \\
\hline Berlin & 3.5 & iss030-e-085815 & $22: 36$ \\
Warsaw & 1.7 & iss030-e-085827 & $22: 38$ \\
London & 9.0 & iss030-e-085899 & $23: 10 *$ \\
Amsterdam & 1.1 & iss030-e-085908 & $00: 11$ \\
Paris & 10.6 & iss030-e-085807 & $22: 35$ \\
Madrid & 6.6 & iss030-e-082053** & $03: 23$ \\
\hline
\end{tabular}
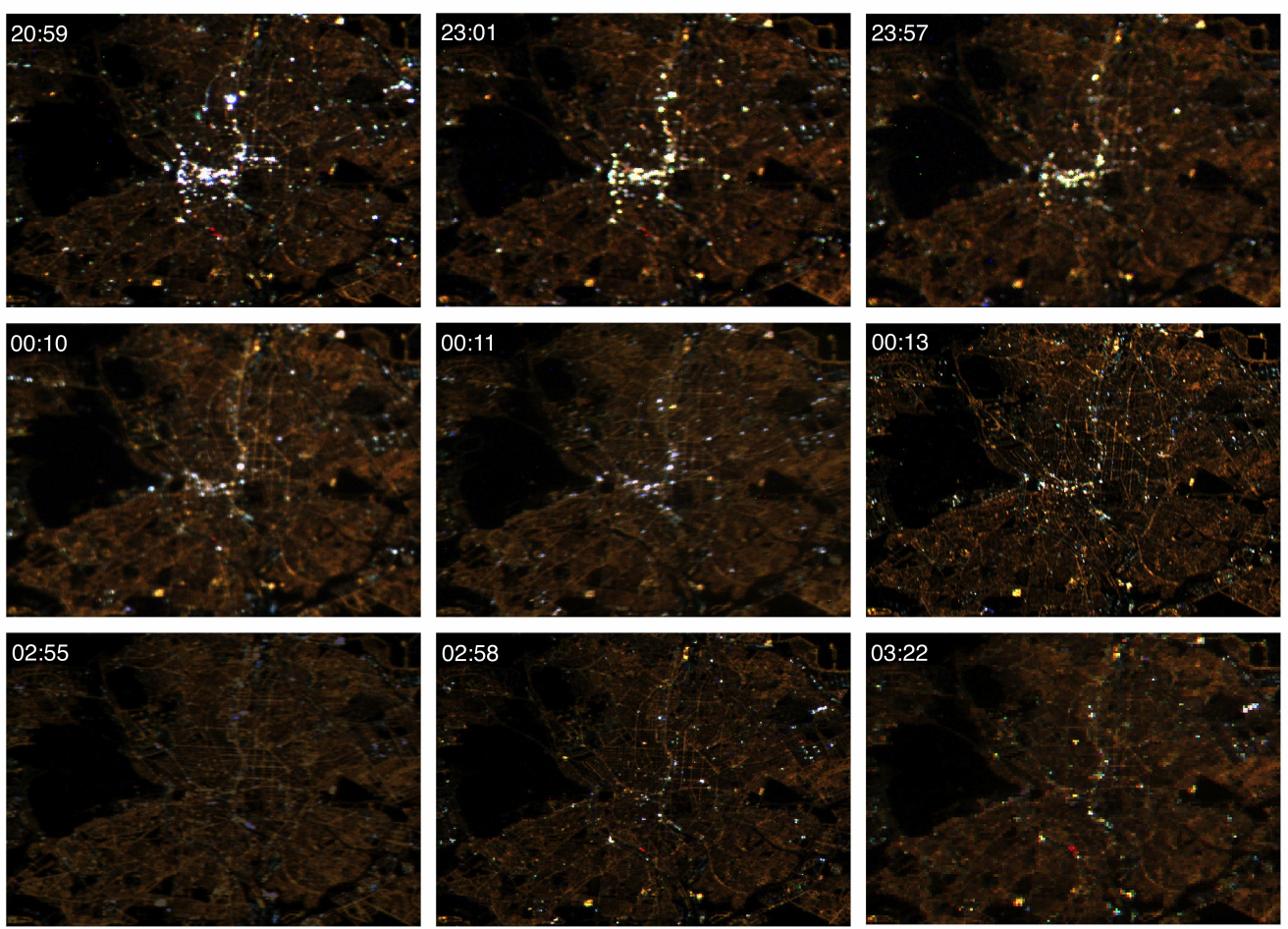

Figure 3. Nine photographs of Madrid at different times of night. The images are arranged to show increasingly late times from top left to bottom right. Images courtesy of the Earth Science and Remote Sensing Unit, NASA Johnson Space Center.

\subsubsection{Observations}

The variation in the individual images in Figures 2 and 3 is so large, that it is possible to gain insights from them simply through visual inspection. The two most obvious differences in Figure 2 are in the variation in color and brightness, both within and between the cities. The street networks in most cities have a relatively uniform color and brightness, and all of the images contain unusually bright points. Large individual structures and facilities, like airports, ports, stadiums and greenhouse complexes are easily visible in the full resolution images. Figure 3 reveals individual bright sources turning off as 
the night progresses, consistent with a reported observation of decreasing sky brightness as the night progresses in Madrid [28].

Table 2. Times and dates of the images of the evolution of Madrid.

\begin{tabular}{cccc}
\hline Image Name & Night of Week & Date (UT) & Local Time \\
\hline iss034e005868 & Saturday & $2012-12-08$ 19:59:33 & $20: 59$ \\
iss030e209454 & Sunday & $2012-04-0821: 01: 12$ & $23: 01$ \\
iss030e209271 & Saturday & $2012-04-0721: 57: 03$ & $23: 57$ \\
iss035e023371 & Thursday & $2013-04-1822: 10: 09$ & $00: 10$ \\
iss026e026495 & Friday & $2011-02-1123: 11: 54$ & $00: 11$ \\
iss032e015065 & Sunday & $2012-08-0522: 13: 58$ & $00: 13$ \\
iss034e058838 & Thursday & $2013-02-0801: 55: 32$ & $02: 55$ \\
iss030e188196 & Tuesday & $2012-03-2801: 58: 48$ & $02: 58$ \\
iss030e082053 & Saturday & $2012-02-1202: 22: 47$ & $03: 22$ \\
\hline
\end{tabular}

The color of streets and light points depends mainly on the lighting technology that is in use. Streets that appear orange, such as those in Madrid, are most likely lit by either high or low-pressure sodium lamps. White areas are lit by mercury vapor, fluorescent, metal-halide or LED lamps (see [29] for detailed information about lamp spectra). Figure 4 shows that the divided history of Berlin can still be seen in the color difference of many of the smaller streets in the former East (orange) and West (white). The bright spots in the three figures are often due to architectural lighting that shines directly into space rather than on the building itself. These spots often appear blue, but this is likely due to the color balance of the image. Such lights would most likely appear "cold white" if viewed by eye.

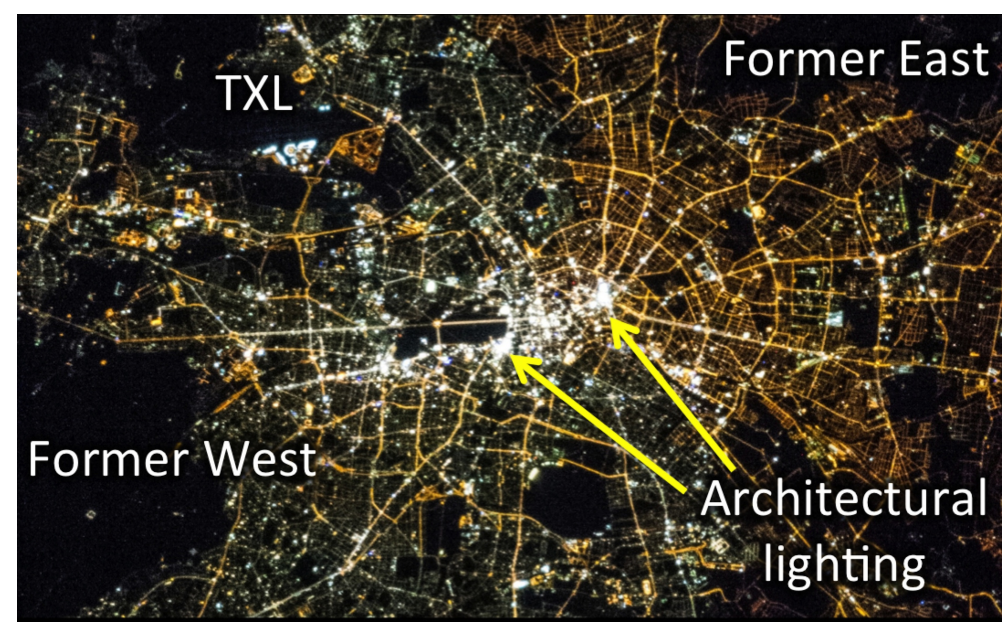

Figure 4. Cropped portion of another image of Berlin taken from the ISS (iss035e17210). Berlin's Tegel airport is labeled with "TXL". Image courtesy of the Earth Science and Remote Sensing Unit, NASA Johnson Space Center. 
In all cities, the brightest individual points tend to be located near the city center. The radiance of the street networks are strikingly different, with Berlin far darker than the other capitals and Madrid far brighter. Illuminated highways are evident in only some of the cities. For example, much of the M25 motorway around London appears to be lit, while Berlin's Autobahn 10 ring (portions of which have no speed limit) is unlit (Figure 2). With the exception of Warsaw, the street networks of outlying communities appear to have similar radiances to the capital.

\subsubsection{Commentary}

Nighttime images emphasize areas of human activity. Transportation networks (roads, airports and seaports) are thrown in stark relief against rivers, parks and unlit rooftops. Such images may allow for a more intuitive understanding of urban processes than other maps, as regions of high economic activity are naturally highlighted (further discussion of ISS images of cities worldwide is available in German [30]). The images also emphasize the degree of light-induced fragmentation of urban nightscapes and could reveal potential migration barriers for nocturnal animals.

The images demonstrate that there are considerable differences in lighting norms between the cities. The imprint of 40 years of divided lighting management remains visible in Berlin, despite nearly a quarter century since the German reunification. Berlin also still has nearly 40,000 gas lanterns in service [31], and these areas appear to be almost unlit in the composite image (they are visible in the full resolution image). The Berlin Senate studied accidents from 2006-2008 and found that street lighting characteristics had no significant influence on accident rates. On the basis of this and other considerations, Berlin's lighting policy document advises careful use of light under the guiding principle "only as much light as is sensible and necessary" [32]. Berlin's success in maintaining public safety with conservative light levels may suggest that other cities are consuming more light than is necessary.

Recent papers have used aerial $[9,10]$ and satellite [33] imagery to study light emitted towards space in detail. Kuechly et al. [9] found that understanding the sources of light requires images with a resolution of at least 10 meters. Continued improvement of the nighttime imaging capabilities of ISS-mounted devices appears to be a relatively low-cost way to acquire unique remotely-sensed datasets. Future upgrades to the system should include automatic communication of station telemetry to the camera system to improve tracking, precise timestamping to allow automated georeferencing, cooled CCD cameras to reduce noise and regular stellar photometry observations for calibration. A hyperspectral system would provide a wealth of data, making assessment of lamp type and estimates of energy consumption far easier.

\subsection{Case Study 2: Community Light Use in Germany and the USA}

The first case study showed that there is considerable variation in the brightness of cities. This case study examines the relationship between integrated upward directed light and population on a city-size scale. The VIIRS DNB data are used to compare thousands of communities' data from a single instrument. The USA is an ideal study site due to its extremely large area, population and detailed census information. Germany was chosen as a comparison country, because although it has a 
similar wealth and development level as the USA, it has a reputation within Europe for conservative lighting practices.

\subsubsection{Background}

It has long been known that in regions with similar levels of development within a single country, the total upward light output of the city is strongly related to its population (e.g., [34]). This relationship has been studied using data from DMSP, for example, by defining a "sum of lights" (SOL) as the sum of all of the light detected to be emitting from within the bounds of a country, state, county or city $([6,13,35,36])$. The community development level has been found to play a central role in determining both lit area [37] and how much light is emitted per capita. Differences in SOL per capita between high income countries, however, have received little study.

This case study examines differences in the SOL between German and American cities and between cities located in the former East and West of Germany. The fact that VIIRS DNB data are calibrated and do not experience saturation in urban cores is expected to improve the quality of such analyses. To the best of our knowledge, this is the first published SOL study that uses DNB data, as well as the first ever such analysis of German cities.

\subsubsection{Dataset}

The municipality association for the USA used the 2010 TIGER/Line $($ places (incorporated places, census designated places (CDP) or consolidated cities) with demographic data (population) (geography: U.S. Census Bureau). Communities in Puerto Rico and Alaska are excluded from the analysis. For Germany, the 2011 administrative boundaries (Verwaltungsgemeinde VG) with population numbers (scale 1:250,000 (VG250)) (Bundesamt für Kartographie und Geodäsie BKG 2012) were used [38]. Information about affiliation before the German reunification was added as a new attribute to the dataset (former East or West Germany). Berlin was included as a single city classified as being in the former East.

The German data differ from the American data in that the entire land area of Germany is divided among the "cities", whereas in the USA, city boundaries normally include only the area within the town limits. Because of this, light sources located outside of city boundaries (e.g., refineries) may not be included in the U.S. dataset. The U.S. dataset contains extremely small villages, but in Germany, small communities are bundled together, with only 84 having a population smaller than 2000 inhabitants. An alternate German dataset was investigated, but not used, because the different federal states had considerable variation in the typical size of the defined administrative zones.

The light dataset was the two-month composite of DNB data released by the Earth Observation Group that includes moon-free data taken in 2012 from 18-26 April and 11-23 October [21]. This is a preliminary data product, which contains lights associated with fires, gas flares, volcanoes, aurora and background noise. Data from Alaska were observed to have many extremely bright outliers, possibly due to aurora or gas flares, and were therefore excluded.

The VIIRS DNB global map of near-zenith directed radiance was reprojected to a Lambert azimuthal equal area projection with a nearest neighbor algorithm and a raster cell size of $250 \mathrm{~m}$ in 
ESRI ArcGIS 10.1. The sum of light was found for each city by summing the DNB radiance (in $\mathrm{nWcm}{ }^{-2} \cdot \mathrm{sr}^{-1}$ ) for pixels whose centroids fall inside the city boundaries. At the edges of cities, cells are included if the city boundary polygon contains the cell center. Because this technique only integrates light emitted towards the zenith, it is best to think of SOL as an arbitrary unit that is assumed to be highly correlated with total city lumen output.

\subsubsection{Observations}

The scatterplot in Figure 5 compares the observed integrated zenith-directed light to the population of 4492 German (red) and 28,804 American (black) communities on a log-log plot. A fit to cities with populations between approximately 2500 and 250,000 is shown for each country. Earlier, more limited studies have fit such data according to a linear relationship, $\mathrm{SOL}=a \times p^{1}$, where $a$ is a constant related to a typical "lumens per capita" emission (e.g., [34,36]) and $p$ is the city population. Neither of these datasets are fit best with a simple "lumens per capita" measure, although the difference from strict proportionality is not great. The two plotted lines are $\mathrm{SOL}_{\mathrm{USA}}=9.9 \times 10^{-3} \times p^{1.05}$ and $\mathrm{SOL}_{\text {Germany }}=1.5 \times 10^{-2} \times p^{0.89}$. These fits describe the general trend in each country, but it should be kept in mind that since the data is plotted on a log-log scale, there is actually a great deal of variation from city to city, and the value of the exponent has some sensitivity to the decision of the population range over which the fit is performed.

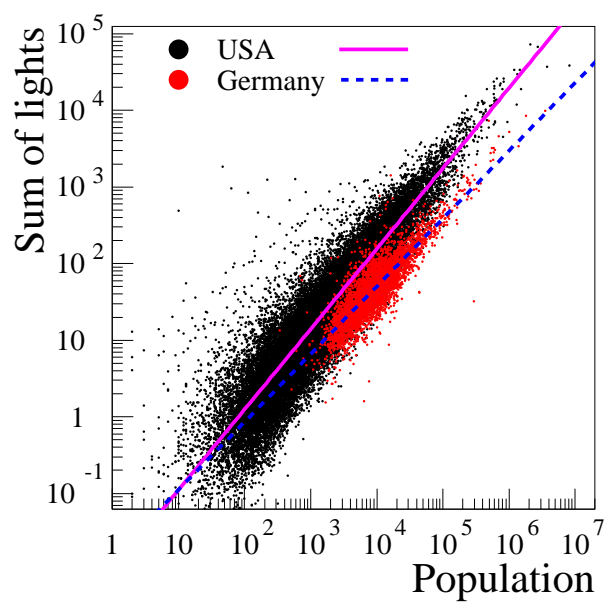

Figure 5. The VIIRS Day-Night Band (DNB) sum of lights (SOL) for 28,804 American and 4492 German communities plotted against population. Trend lines for the two datasets are plotted. If upward lumens/capita were a constant, the trend lines would have equal slopes of one, and the intercept would specify the proportionality constant. The large spread of the data shows that while population is important, it is not the only variable that determines SOL.

The sum of lights is far larger for American cities than for German cities of equivalent population, and the trend in light/capita with increasing population is opposite. Larger American cities are brighter per capita than smaller towns, while the reverse is the case for Germany. Based on the trend lines, an American town with 10,000 inhabitants typically has an SOL approximately three-times greater than an equivalent German town. This difference grows with population: a typical American city of 100,000 
has a SOL more than five-times greater than the equivalent German city. The trend line appears to underestimate the light output of very large cities, but nevertheless, Chicago and Los Angeles have an SOL/capita that are nine and 3.5 times larger than Berlin, respectively.

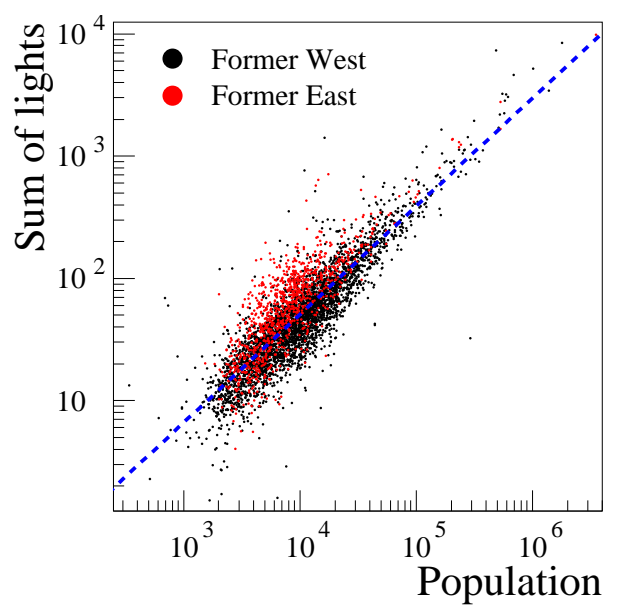

Figure 6. The VIIRS DNB sum of lights is plotted against population for communities in the former East and former West Germany. The trend line from Figure 5 for all German cities is shown.

Figure 6 compares the light output of German cities located in the former West (black) or East (red). The former East is observed to emit more light per capita than the former West. Compared to the trend for all of Germany, 780 of 1008 former eastern communities (77\%) are above the trend line, while in the former West, only 1390 of 3484 (40\%) are above the trend. Within the United States, communities with SOL/capita similar to that of Germany are generally located in the west coast and northeastern states.

\subsubsection{Commentary}

The remarkable difference between American and German cities shown in Figure 5 raises several questions. Most importantly, could there be some systematic effect in the data collection or analysis that explains the difference, or is it real? If the effect is real, then what is the reason for the difference? Why do "upward lumens/capita" grow with increasing population in the USA, but decrease in Germany? Additionally, does the difference in uplight imply a difference in energy consumption?

There are at least four effects that could give rise to a systematic error in the observed sum of lights. First, the American cities did not include the entire land area of the country, while the German "cities" did (see Section 2.2.2). This increases the SOL for German cities and, therefore, cannot explain the observed difference. Second, airglow in Earth's atmosphere contributes to the DNB observation [39], so a difference in airglow over the USA and Germany would lead to different SOL values. This difference was likely not present in the DMSP data, due to its lower sensitivity, but should be carefully considered when developing "stable lights" products for VIIRS DNB. Relatedly, any error in the DNB zero point calibration would necessarily cause an area-dependent error in SOL. However, since the two-month composite dataset contains only positive values, this error would be expected to increase the SOL for German cities rather than American cities. Third, the typical atmospheric extinction varies with location 
and especially altitude. This could make sea level sites, for example, appear darker by several percent, but could not explain differences of a factor of two or more. Fourth, it is likely that the radiance distribution of artificially-lit patches of Earth follows a power-law distribution (see, e.g., Figure 7 in [9]). Digitization of the analog radiance signal is therefore more likely to round down than to round up, and this would lead to a small ( $<1$ bit) systematic dimming of all artificially-lit areas. This error would be proportional to the lit area, but this would act only to decrease the contribution of lights outside German towns. The difference between the countries therefore cannot be explained by these potential systematic errors.
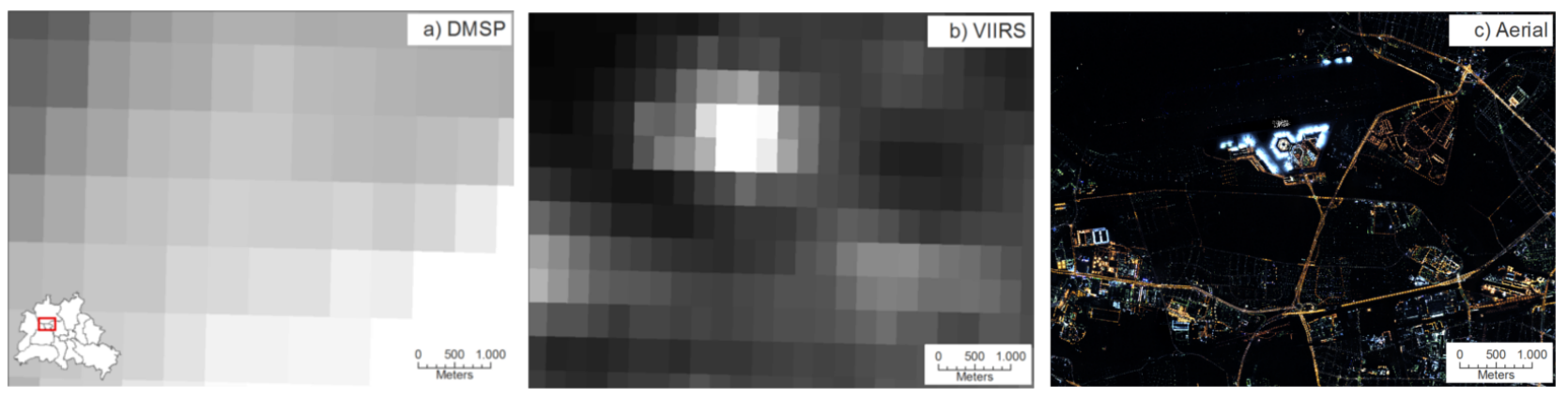

Figure 7. Images of Berlin's Tegel airport at three different resolutions. (a) Defense Meteorological Satellite Program-Operational Linescan System (DMSP) (2010); (b) VIIRS DNB; (c) aerial photography. The inset at the bottom left shows the area of Berlin displayed in each of the three panels. The resolution of DMSP was too coarse to identify light sources smaller than the city scale. Image and data processing by NOAA's National Geophysical Data Center. DMSP data collected by the U.S. Air Force Weather Agency.

Assuming that the difference in SOL per capita is real, differences between the cityscapes may be the cause. As was shown in Case Study 1, cities have lamps with differing light outputs, spectra and angular emission properties. The DNB is not particularly sensitive in the blue range $(<500 \mathrm{~nm})$, but does have sensitivity in the near-infrared. Because of this, lamps with different spectra, but identical lumen outputs, would produce different DNB radiances. Lamps that emit light directly upwards may sometimes also be important in some cases (Figure 1).

Differences in architecture and city planning related to history and climate could be responsible for both the differences between the countries and the variation within each country (e.g., typical street illuminance, street width, building height, prevalence and typical radiance of advertising and architectural lighting, as well as vegetation cover). For example, if streets had identical surface illuminance, wider streets in a younger sprawling American city would produce a larger observed SOL than for denser, old-world cities. Similarly, newer cities and subdivisions, especially those in the American West, may tend to have younger and less abundant tree cover. A final possibility is that German streets may be simply less brightly lit than American streets. As revealed by the color difference of the former East and West Berlin in Figure 4, much of the public lighting in Germany is decades old. In fact, about a third is believed to be more than 20 years old [40].

The data in Figure 5 display a considerable spread around the trend lines, indicating that factors other than population are also important in determining light emission. About $12 \%$ of American cities and 
$5 \%$ of German cities with populations over 10,000 have an SOL more than double that of the country's trend line. Future studies could examine a selection of similarly-sized cities to uncover the reasons that they emit larger or smaller amounts of light. Such studies would be useful for policy makers interested in minimizing energy use and skyglow and may also shed light on why light per capita appears to grow with population in the USA, but reduce with population in Germany.

Figure 6 demonstrates that even within a country, political, cultural, economic and/or historical differences (i.e., the cultural footprint) can influence regional light emission per capita. Internal migration from the former East to the former West since 1989 means that even if street lighting had stayed the same in both regions, light output per capita would have changed in the observed direction. However, the difference cannot be entirely explained by this, since former Eastern cities are about $57 \%$ brighter than the trend line; the population loss from the former East through 2006 was only about 10\% [41], and street light only makes up about $1 / 3$ of the zenith directed light from Berlin [9]. Another possible explanation for the difference could be the typical lamp technology in use (e.g., the color difference between East and West Berlin) or different typical dates of the last replacement in the former East and West (e.g., aged mercury vapor lamps vs. modern LEDs).

\subsection{Case Study 3: The Brightest Large-Scale Light Sources}

The second case study considered the light output of the entire cities. This case study examines what type of structures are the brightest individual large-scale light sources within a city, using the VIIRS DNB data. To sample a wide range of development levels and city populations, the world's 30 megacities and Europe's 46 capital cities were investigated.

\subsubsection{Background}

Figure 7 shows nighttime views of the area around Tegel airport in Berlin, Germany, at night, at three different resolutions ( $c f$. Figure 4). Panel (a) is the older DMSP ( 2.7 km, reprojected to a 30" grid); Panel (b) is the VIIRS preliminary two-month data product ( $\sim 750 \mathrm{~m}$, reprojected to a 15 " grid); and Panel (c) shows high resolution aerial photography $(\sim 1 \mathrm{~m})$. While the VIIRS data are not able to resolve individual streets, large, brightly-lit structures, like airports and stadiums, are clearly visible. These structures can be responsible for a significant fraction of the total light emitted upward by a city: in Berlin, Tegel airport is responsible for about $4 \%$ of the total uplight in the $319 \mathrm{~km}^{2}$ analyzed by Kuechly et al. [9].

As shown in Case Study 2, total upward directed light is approximately proportional to population. Population density, however, increases with population, so the average radiance of cities must therefore also increase with population. The reasons for this increase have not yet been investigated. The VIIRS DNB data offer the first opportunity to examine on a global spatial scale what types of structures are responsible for the brightest areas within cities.

\subsubsection{Dataset}

The VIIRS DNB two-month composite was used to identify the brightest location (peak radiance) in or nearby each of the world's 30 megacities (population $>10$ million) and each of the 46 European 
capitals. After finding the brightest DNB pixel in each city, the location was examined using Google Earth to try to identify what type of structure was responsible. The peak radiance for each of the world's 10 largest airports by passenger volume (estimates from 2012 [43]) was also found. Tables containing the data are available in the Supplementary Information. More detailed information about the dataset, including tables listing each city, is available in [42] (in German).

\subsubsection{Observations}

Due to the preliminary nature of the DNB dataset, the relatively small number of cities examined and that fact that this is an outlier analysis, it would be premature to perform statistical analyses on this dataset. Nevertheless, the data hint at potential correlations that future studies may want to examine.

The brightest locations were most commonly city centers, airports, sea ports, stadiums and industrial facilities. Differences between developing and industrialized countries were observed. In developing countries, the brightest areas in megacities were associated with industry (eight of 15 had airports and sea ports as the brightest location), whereas in industrialized countries, the brightest lights were associated with leisure and commerce (eight of 15 had city centers or stadiums as the brightest location). Nearly two thirds of European capitals had city centers or stadiums as the brightest location. Figure 8 shows the VIIRS DNB two-month composite for the same six European cities presented in Figure 2. The VIIRS overpass occurs later at night than most of the images in Figure 2. In Amsterdam's case, this means there is considerable extra light from greenhouses that turn lights on after midnight.
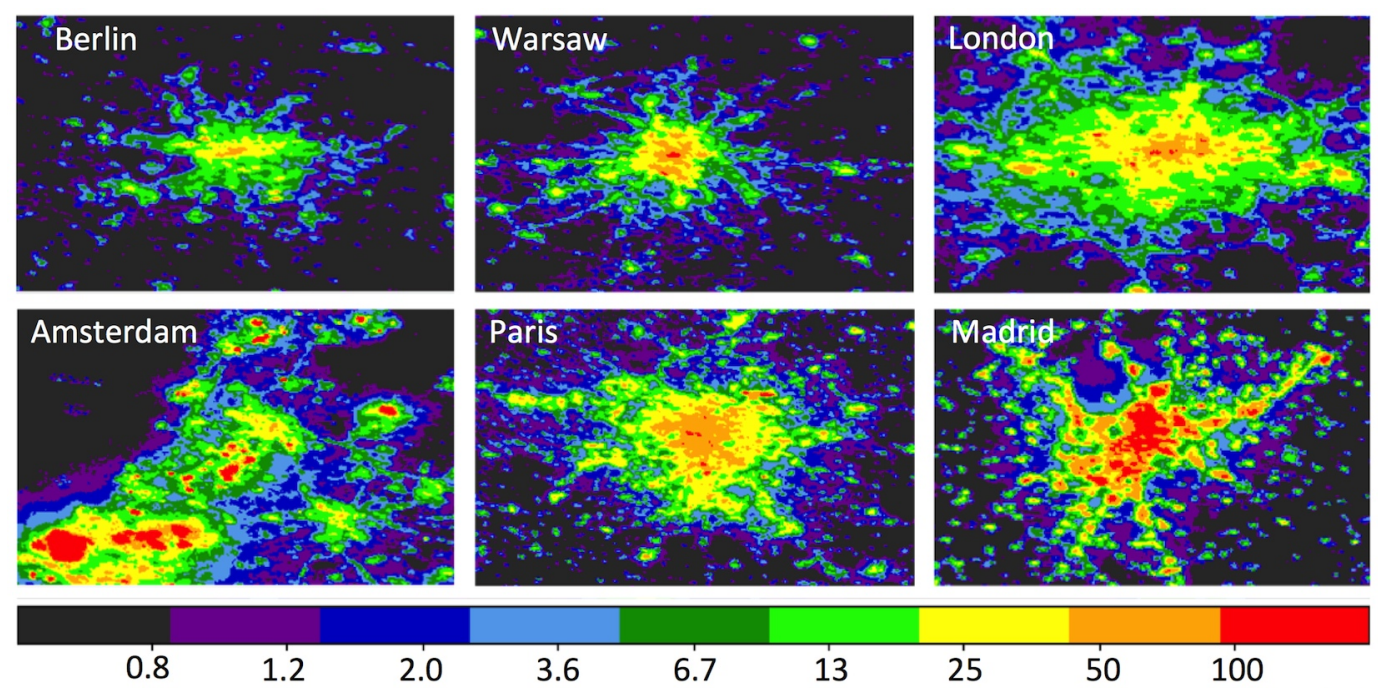

3.6

6.7

13

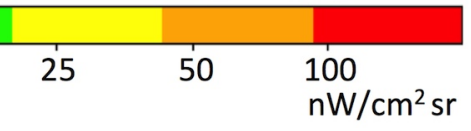

Figure 8. Upwelling radiance of six European cities in the VIIRS two-month composite dataset, with a logarithmic color scale. The data are reprojected on a 15 -arcsecond grid, which slightly distorts each city's shape. Data courtesy of the Earth Observation Group, NOAA National Geophysical Data Center.

Consistent with earlier observations [37], it appears likely that there is a relationship between peak radiance and the development status of the megacities. There does not appear to be any relationship between peak radiance and population in the megacities, but a weak relationship with population may 
potentially exist in the European capitals. The data hint at a possible difference in lighting culture between capitals in Western and Central Europe: with the exception of only (bright) Warsaw and (dim) Amsterdam, the brightest locations in each Western capital were brighter than those in each Central capital. This is despite the fact that the Western cities of Brussels (population 1.2 M), Dublin (530 k), Luxemburg (103 k) and Monaco (36 k) are considerably smaller than each of Berlin (3.5 M), Budapest (1.8 M), Vienna (1.7 M) and Prague (1.3 M).

The peak radiances observed for the world's ten largest airports are listed in Table 3. Very large variations were observed, with Chicago (ORD) almost 4.5-times brighter than Tokyo (HND), despite the fact that they carried nearly the same number of passengers in 2012.

Table 3. Peak radiance of the world's ten largest airports. The final column lists the peak radiance relative to that of Tokyo's HND.

\begin{tabular}{cccc}
\hline Airport & Passengers (M) & Radiance (nW/cm $\left.{ }^{2} \mathbf{s r}\right)$ & Relative to Tokyo \\
\hline Atlanta (ATL) & 95.5 & 197 & 3.6 \\
Beijing (PEK) & 81.9 & 237 & 4.3 \\
London (LHR) & 70.0 & 82 & 1.5 \\
Tokyo (HND) & 66.8 & 55 & 1.0 \\
Chicago (ORD) & 66.6 & 246 & 4.5 \\
Los Angeles (LAX) & 63.7 & 165 & 3.0 \\
Paris (CDG) & 61.6 & 179 & 3.3 \\
Dallas/Fort Worth (DFW) & 58.6 & 217 & 3.9 \\
Jakarta (CGK) & 57.8 & 62 & 1.1 \\
Dubai (DXB) & 57.7 & 193 & 3.5 \\
\hline
\end{tabular}

\subsubsection{Commentary}

The VIIRS DNB makes it possible for the first time to identify large-scale bright sources of waste light worldwide, to measure the light output of such facilities and to track how this light output changes over time. The DNB data could therefore be of considerable use for cities aiming to reduce energy consumption and the emission of waste light. Reductions or increases in waste light output as a result of lamp change can also now be measured, provided that the spectral power distribution and angular emission profile of the lamps is known.

The analysis presented here demonstrates that there are considerable differences in the radiance of the brightest sources of light in large cities, even among highly-developed countries. The data indicate that brightly lit city centers are not necessary for robust nighttime economic activity to take place: both Berlin and Amsterdam are known for their active nightlife, yet each have conservatively lit city centers. The purpose of area lighting at airports is identical worldwide: providing sufficient light for the safe parking and service of aircraft. The data may indicate that, in some cases, airports are overlit, although it is also possible that large values are related to direct uplight or a greater fraction of the lit area being contained in a single DNB pixel. Airports are a particularly attractive target for lighting interventions 
to reduce energy use and waste light, because they are large consumers of light and fewer stakeholders are involved.

More quantitative future comparisons should take into account the lamp spectra (if known), surface spectral reflectivity and the entire area of the facilities under study. Policymakers interested in reducing energy consumption and waste light emission could use such data to investigate whether such facilities are overlit compared to others worldwide [44]. Although DNB has poor resolution compared to aerial photos, statistical analysis of the data on a large spatial scale could be used to understand the most important sources of light emission [45,46]. Future analyses similar to Case Study 2 could also investigate whether the observed difference in the brightest areas of Western and Central European capitals is due to cultural differences in lighting.

\section{Results and Discussion}

The three case studies demonstrate that there are large variations in how light is used worldwide and that the data delivered by the VIIRS DNB and astronaut photographs can be used to quantitatively evaluate these differences. The major advantages of the new data over that from older sensors are their much improved resolution, higher sensitivity and the fact that they are calibrated (DNB) [20] or at least calibratable (photos) [26]. Night imagery is likely to be extremely useful in fields as disparate as economics, ecology, epidemiology and atmospheric science. The street-level imagery available from the ISS should prove especially useful in epidemiology, and could potentially resolve the question of whether neighborhood light levels are a cause or correlate of diseases like breast cancer [47]. The case studies have also demonstrated that the data have limitations that will provide some challenges for applying them to some fields (Table 4). These challenges are related to the great variation in artificial light emission with spectrum, time, emission direction and location. Each of these factors is considered below.

The spectral sensitivity of the DNB is quite different from that of the human visual system, with little sensitivity below $500 \mathrm{~nm}$. This will make comparisons of cities and the study of lighting trends increasingly problematic, because street lighting worldwide is currently being replaced by "white" LEDs, which generally have considerable emission in the range 450 to $480 \mathrm{~nm}[29,48]$. Because of this, a transition from low pressure sodium to LED lighting could appear as a large reduction in DNB radiance, even if the luminance at the street level slightly increased. This problem may pose a particular challenge to studies of energy and socio-economic parameters that rely on time series or comparisons between different regions. The problem may be even more critical for epidemiological studies, because the response of the human circadian system peaks in a spectral range that both the DMSP and VIIRS DNB do not image [49].

The spectral information problem could be minimized to some extent through synergistic application of both datasets. Color information from the ISS photographs could be used to approximately identify the mix of lighting types used in a region corresponding to a single pixel in the DNB stable lights product $[10,29]$. The DNB radiance could then be turned into an estimated spectral radiance for the pixel. Spectral radiances would be of greater use in analyses, such as modeling skyglow [16,50], estimating energy consumption [29] and epidemiological studies [18]. 
Table 4. Opportunities and challenges in the selection of the research fields where the new sources of nighttime light data are likely to be useful.

\begin{tabular}{|c|c|c|}
\hline Field & Opportunities & Challenges \\
\hline atmospheric science & $\begin{array}{l}\text { visible band remote sensing } \\
\text { e.g., aerosol properties }\end{array}$ & $\begin{array}{l}\text { understanding sources } \\
\text { variable air mass }\end{array}$ \\
\hline ecology & higher sensitivity in "dark" areas & $\begin{array}{l}\text { relationship between upward emitted } \\
\text { light and environmental exposure }\end{array}$ \\
\hline energy & $\begin{array}{l}\text { no saturation } \\
\text { calibrated data } \\
\text { variable overpass times }\end{array}$ & $\begin{array}{l}\text { changes in lamp properties } \\
\text { (spectra \& angle) } \\
\text { albedo/tree cover }\end{array}$ \\
\hline epidemiology & street-level information & $\begin{array}{l}\text { spectral information } \\
\text { angular emission direction } \\
\text { radiance calibration } \\
\text { overpass time }\end{array}$ \\
\hline light pollution & highly reliable data & all of the above \\
\hline socio-economic parameters & $\begin{array}{l}\text { higher spatial resolution } \\
\text { higher sensitivity } \\
\text { no saturation }\end{array}$ & $\begin{array}{l}\text { changes in lamp properties } \\
\text { angular distribution }\end{array}$ \\
\hline
\end{tabular}

Case Study 1 showed that city light is not constant, but changes dynamically over the course of the evening. Skyglow studies have observed such changes, with associated changes in spectra [51]. Researchers using future DNB "stable lights" products should keep in mind that the satellite overpass time is variable and occurs after local midnight. Stadiums and other sources that operate lights on a curfew may potentially not appear lit in stable light products or may have radiances that represent an average over several days and overpass times. Data from ISS photos may provide additional information by determining trends in lighting shut-offs. Some areas reduce light emission as the night progresses, and these effects are likely to become stronger as more areas introduce legislation of light at night [44]. Finally, seasonal changes can cause great variation in the fraction of light that can escape to space (e.g., snow and foliage cover). This is of particular importance at high latitudes, where "yearly" DNB composites will have a winter bias, due to summertime overpasses during twilight not contributing to the average.

In general, neither VIIRS nor the ISS photos are taken directly at nadir, but rather at some angle $\theta$. As $\theta$ increases from zero, the light propagates through increasing air mass. This increases the optical depth and red-shifts the spectrum of the direct beam. In addition, the light emitted upwards by cities is not Lambertian, but, rather, dependent on $\theta[52,53]$. This dependence will change as older lamps are replaced, because newer lamps tend to emit a smaller fraction of light directly upwards. At angles much larger than zenith, light is strongly shaded by buildings. Radiance measurements from DNB and the ISS should therefore be expected to have strong dependencies on both the nadir and azimuth direction. Astronauts should place a priority on imaging cities that pass near the station's nadir. 
Case Study 2 demonstrated that there are considerable differences in light emission, both between and within countries. Some analyses, for example, the retrieval of aerosol properties, are sure to require a careful characterization of the light sources (spectra, intensity and emission direction) specific to the location. Lack of saturation in DNB will improve understanding of urban lighting and will expand the range of possible socioeconomic studies. The higher sensitivity of DNB will expand the regions of Earth over which faint levels of artificial light are visible. This may be particularly important for understanding the ecological impacts of artificial light [54,55].

Lighting accounts for about $19 \%$ of total electrical energy consumption [56], and despite improvements in luminous efficiency, per capita consumption of light has remained near $0.7 \%$ of GDP [57]. The combination of increasing GDP and improving luminous efficiency has led to increases in the amount of light shone into space [13,58-62]. The major differences in light emitted upward by Germany and the USA suggest that such a trend need not necessarily continue, as the difference in light use between the countries is considerably larger than the difference in per capita GDP. Future studies should examine the roles that factors, such as population density, automobile use, street width, vegetation and building height, play in determining how bright cities appear from space.

By examining and contrasting cities that have anomalously large and small amounts of uplight, more effective strategies for minimizing waste light could be developed. The DNB data could also be used to examine the effectiveness of light pollution laws [44] or city planning strategies, like the Berlin Lichtkonzept [32], at reducing waste light.

\section{Conclusions}

Artificial light at night is often far brighter than natural and reflected celestial light, so nighttime visible band images of Earth highlight human activity in a way that daylit scenes do not, especially in urban areas. Newly available imagery from the International Space Station and VIIRS Day-Night Band has the potential for application across many scientific disciplines. The intensity and spectra of artificial light at night has rapidly changed over the last century, and the new imagery will allow global tracking of these changes for the first time.

Lighting management appears to impart a cultural footprint upon nighttime views of cities and nations. The case studies presented here show that there are large differences in current patterns of light use, even between countries with highly-developed economies. American cities emit far more light than German cities of equivalent size, and the brightest areas of Central European capitals are fainter than those in the West. Even within a single country, historical forces influence lighting: cities in the former East Germany are more brightly lit than those in the former West. Further study of the light sources, for example characterization of the mix of lighting technologies in use, will allow more in-depth understanding of these differences and will make night light data even more reliable and useful for researchers.

\section{Acknowledgments}

This paper was conceived of and planned during activities of the EU COST Action ES1204 (Loss of the Night Network). The researchers were supported by grants from the German Federal Ministry of 
Education and Research (BMBF-033L038A), the Berlin Senate Department for Economics, Technology and Research (Lichtimmissionen im öffentlichen Raum) and an FPU grant (Formación de Profesorado Universitario) from the Spanish Ministry of Science and Innovation (MCINN) to Alejandro Sánchez de Miguel. The support of AYA2012-31277 and AYA2013-46724-P and the Spanish Network for Light Pollution Studies (AYA2011-15808-E) is also acknowledged.

\section{Author Contributions}

Christopher C.M. Kyba wrote the first draft. Alejandro Sánchez de Miguel and Jaime Zamorano assembled Case Study 1, Helga Kuechly, Christopher C.M. Kyba, Franz Hölker and Jürgen Fischer assembled Case Study 2. Stefanie Garz, Christopher C.M. Kyba and Jürgen Fischer assembled Case Study 3. All authors planned the manuscript and provided input at all stages of writing.

\section{Conflicts of Interest}

Christopher C.M. Kyba is a member of the Board of Directors of the International Dark-Sky Association.

\section{References}

1. Doll, C.N.; Muller, J.P.; Morley, J.G. Mapping regional economic activity from night-time light satellite imagery. Ecol. Econ. 2006, 57, 75-92.

2. Elvidge, C.; Baugh, K.; Anderson, S.; Sutton, P.; Ghosh, T. The Lumen Gini Coefficient: A satellite imagery derived human development index. Soc. Geogr. Discuss 2012, 8, 27-59.

3. Elvidge, C.D.; Sutton, P.C.; Ghosh, T.; Tuttle, B.T.; Baugh, K.E.; Bhaduri, B.; Bright, E. A global poverty map derived from satellite data. Comput. Geosci. 2009, 35, 1652-1660.

4. Ghosh, T.; Powell, R.L.; Elvidge, C.D.; Baugh, K.E.; Sutton, P.C.; Anderson, S. Shedding light on the global distribution of economic activity. Open Geogr. J. 2010, 3, 148-161.

5. Levin, N.; Duke, Y. High spatial resolution night-time light images for demographic and socio-economic studies. Remote Sens. Environ. 2012, 119, 1-10.

6. Elvidge, C.D.; Baugh, K.E.; Kihn, E.A.; Kroehl, H.W.; Davis, E.R.; Davis, C.W. Relation between satellite observed visible-near infrared emissions, population, economic activity and electric power consumption. Int. J. Remote Sens. 1997, 18, 1373-1379.

7. Lo, C. Modeling the population of China using DMSP operational linescan system nighttime data. Photogramm. Eng. Remote Sens. 2001, 67, 1037-1047.

8. Sutton, P.C.; Elvidge, C.; Obremski, T. Building and evaluating models to estimate ambient population density. Photogramm. Eng. Remote Sens. 2003, 69, 545-553.

9. Kuechly, H.U.; Kyba, C.C.M.; Ruhtz, T.; Lindemann, C.; Wolter, C.; Fischer, J.; Hölker, F. Aerial survey of light pollution in Berlin, Germany, and spatial analysis of sources. Remote Sens. Environ. 2012, 126, 39-50.

10. Hale, J.D.; Davies, G.; Fairbrass, A.J.; Matthews, T.J.; Rogers, C.D.; Sadler, J.P. Mapping lightscapes: Spatial patterning of artificial lighting in an urban landscape. PLoS One 2013, doi:10.1371/journal.pone.0061460. 
11. Zhao, N.; Ghosh, T.; Samson, E.L. Mapping spatio-temporal changes of Chinese electric power consumption using night-time imagery. Int. J. Remote Sens. 2012, 33, 6304-6320.

12. Doll, C.H.; Muller, J.P.; Elvidge, C.D. Night-time imagery as a tool for global mapping of socioeconomic parameters and greenhouse gas emissions. AMBIO 2000, 29, 157-162.

13. Elvidge, C.D.; Ziskin, D.; Baugh, K.E.; Tuttle, B.T.; Ghosh, T.; Pack, D.W.; Erwin, E.H.; Zhizhin, M. A fifteen year record of global natural gas flaring derived from satellite data. Energies 2009, 2, 595-622.

14. Stark, H.; Brown, S.; Wong, K.; Stutz, J.; Elvidge, C.; Pollack, I.; Ryerson, T.; Dube, W.; Wagner, N.; Parrish, D. City lights and urban air. Nat. Geosci. 2011, 4, 730-731.

15. Cinzano, P.; Falchi, F.; Elvidge, C.D. The first World Atlas of the artificial night sky brightness. Mon. Not. R. Astron. Soc. 2001, 328, 689-707.

16. Aubé, M.; Kocifaj, M. Using two light-pollution models to investigate artificial sky radiances at Canary Islands observatories. Mon. Not. R. Astron. Soc. 2012, 422, 819-830.

17. Kyba, C.C.M.; Wagner, J.M.; Kuechly, H.U.; Walker, C.E.; Elvidge, C.D.; Falchi, F.; Ruhtz, T.; Fischer, J.; Hölker, F. Citizen science provides valuable data for monitoring global night sky luminance. Sci. Rep. 2013, doi:10.1038/srep01835.

18. Kloog, I.; Haim, A.; Stevens, R.G.; Barchana, M.; Portnov, B.A. Light at night co-distributes with incident breast but not lung cancer in the female population of Israel. Chronobiol. Int. 2008, 25, $65-81$.

19. Huang, Q.; Yang, X.; Gao, B.; Yang, Y.; Zhao, Y. Application of DMSP/OLS nighttime light images: A meta-analysis and a systematic literature review. Remote Sens. 2014, 6, 6844-6866.

20. Miller, S.D.; Straka, W.; Mills, S.P.; Elvidge, C.D.; Lee, T.F.; Solbrig, J.; Walther, A.; Heidinger, A.K.; Weiss, S.C. Illuminating the capabilities of the suomi national polar-orbiting partnership (NPP) visible infrared imaging radiometer suite (VIIRS) day/night band. Remote Sens. 2013, 5, 6717-6766.

21. National Geophysical Data Center, National Oceanic and Atmospheric Administration. Two Months Composite, 2012. Available online: http://ngdc.noaa.gov/eog/viirs/download_ monthly.html (accessed on 8 August 2013).

22. De Miguel, S.A.; Castaño, J.G.; Zamorano, J.; Kyba, C.C.M.; Pascual, S.; Ángeles, M.; Cayuela, L.; Martin Martinez, G.; Challupner, P. Atlas of astronaut photos of Earth at night. Astron. Geophys. 2014, doi:10.1093/astrogeo/atu165.

23. De Miguel, S.A.; Zamorano Calvo, J.; Gómez Castaño, J. Image Classification of Night Time Images Detected from the International Space Station; Technical Report; Universidad Complutense de Madrid: Madrid, Spain, 2014.

24. Sabbatini, M. NightPod-Nodding Mechanism for the ISS; Technical Report Experiment Record \#9337; European Space Agency: Noordwijk, The Netherlands, 2014.

25. Zamorano, J.; de Miguel, A.S.; Pascual, S.; Castaño, J.G.; Ramírez, P.; Challupner, P. ISS Nocturnal Images as a Scientific Tool against Light Pollution; LICA Report; LICA: Makati, Philippines, 2011. 
26. De Miguel, S.A.; Zamorano, J.; Pascual, S.; López Cayuela, M.; Ocaña, F.; Challupner, P.; Gómez Castaño, J.; Fernández-Renau, A.; Gómez, J.; de Miguel, E. ISS nocturnal images as a scientic tool against light pollution: Flux calibration and colors. In Highlights of Spanish Astrophysics VII; Springer: Berlin, Germany, 2013; Volume 1, pp. 916-919.

27. Central Intelligence Agency. The World Factbook, 2013. Available online: http://www.cia.gov/ library/publications/the-world-factbook/fields/2219.html (accessed on 30 June 2014).

28. De Miguel, S.A. Variación del Brillo del Fondo de Cielo en el Cénit con la Fase y Altura de la Luna. Master's Thesis, Universidad Complutense de Madrid, Madrid, Spain, 2012.

29. Elvidge, C.D.; Keith, D.M.; Tuttle, B.T.; Baugh, K.E. Spectral identification of lighting type and character. Sensors 2010, 10, 3961-3988.

30. Graf, N.; Grube, D.; Henckel, D.; Kniesburges, A.; Kostulski, B.; Ossa, M.M.; Naeth, A.; Oberpichler, A.; Ottrembka, F.; Reiling, J.; et al. LichtGestalten: Analyse-, Gestaltungs-, und Konfliktpotenziale; Technische Universität Berlin: Berlin, Germany, 2013.

31. Berlin Senatsverwaltung für Stadtentwicklung und Umwelt. Gaslaternen in Berlin, 2014. Available online: http://www.stadtentwicklung.berlin.de/bauen/beleuchtung/de/gaslicht (accessed on 26 August 2014).

32. Berlin Senate Department for Urban Development and the Environment. Stadtbild Berlin Lichtkonzept Handbuch, 2011. Available online: http://www.stadtentwicklung.berlin.de/bauen/ beleuchtung/download/Broschuere_Lichtkonzept.pdf (accessed on 18 December 2014).

33. Levin, N.; Johansen, K.; Hacker, J.M.; Phinn, S. A new source for high spatial resolution night time images-The EROS-B commercial satellite. Remote Sens. Environ. 2014, 149, 1-12.

34. Bertiau, F.C.; de Graeve, E.; Treanor, P.J. The artificial night-sky illumination in Italy. Vatican Obs. Publ. 1973, 1, 157-179.

35. Sutton, P.; Roberts, D.; Elvidge, C.; Meij, H. A comparison of nighttime satellite imagery and population density for the continental United States. Photogramm. Eng. Remote Sens. 1997, 63, 1303-1313.

36. Luginbuhl, C.B. Using DMSP night-time imagery to evaluate lighting practice in the American southwest. Preserv. Astron. Sky 2001, 196, 103-106.

37. Sutton, P.; Roberts, D.; Elvidge, C.; Baugh, K. Census from Heaven: An estimate of the global human population using night-time satellite imagery. Int. J. Remote Sens. 2001, 22, 3061-3076.

38. Bundesamt für Kartographie und Geodäsie. Administrative Areas 1:250,000, 2012. Available online: http://tinyurl.com/kplccqm (accessed on 30 June 2013).

39. Miller, S.; Mills, S.; Elvidge, C.; Lindsey, D.; Lee, T.; Hawkins, J. Suomi satellite brings to light a unique frontier of nighttime environmental sensing capabilities. Proc. Natl. Acad. Sci. USA 2012 , 109, 15706-15711.

40. Pepler, W.; Schiller, C.; Khan, T.Q. Kommunen in Neuem Licht; Siebel Druck und Grafik: Lindlar, Germany, 2013.

41. Glorius, B. Go west: Internal migration in Germany after reunification. Belg. Rev. Belg. Géogr. 2010, 3, 281-292.

42. Garz, S. Erste Untersuchung der Nachtaufnahmen von Städten des neuen Satelliten Suomi NPP. Bachelor's Thesis, Freie Universitaet Berlin, Berlin, Germany, 2014. 
43. Mesa, D. 2012 Airport Traffic Report; Technical Report; The Port Authority of NY \& NJ: New York, NY, USA, 2013.

44. Kyba, C.; Hänel, A.; Hölker, F. Redefining efficiency for outdoor lighting. Energ. Environ. Sci. 2014, 7, 1806-1809.

45. Zollweg, J.D.; Gartley, M.; Roskovensky, J.; Mercier, J. Using GIS databases for simulated nightlight imagery. Proc. SPIE 2012, doi:10.1117/12.919510.

46. Olsen, R.N.; Gallaway, T.; Mitchell, D. Modelling US light pollution. J. Environ. Plann. Manag. 2014, 57, 883-903.

47. Kantermann, T.; Roenneberg, T. Is light at night a health risk factor or a health risk predictor? Chronobiol. Int. 2009, 26, 1069-1074.

48. Falchi, F.; Cinzano, P.; Elvidge, C.; Keith, D.; Haim, A. Limiting the impact of light pollution on human health, environment and stellar visibility. J. Environ. Manag. 2011, 92, 2714-2722.

49. Lucas, R.J.; Peirson, S.N.; Berson, D.M.; Brown, T.M.; Cooper, H.M.; Czeisler, C.A.; Figueiro, M.G.; Gamlin, P.D.; Lockley, S.W.; O’Hagan, J.B.; et al. Measuring and using light in the melanopsin age. Trends Neurosci. 2014, 37, 1-9.

50. Cinzano, P.; Falchi, F. The propagation of light pollution in the atmosphere. Mon. Not. R. Astron. Soc. 2012, 427, 3337-3357.

51. Kyba, C.C.M.; Ruhtz, T.; Fischer, J.; Hölker, F. Red is the new black: How the color of urban skyglow varies with cloud cover. Mon. Not. R. Astron. Soc. 2012, 425, 701-708.

52. Luginbuhl, C.B.; Duriscoe, D.M.; Moore, C.W.; Richman, A.; Lockwood, G.W.; Davis, D.R. From the ground up II: Sky glow and near-ground artificial light propagation in Flagstaff, Arizona. Publ. Astron. Soc. Pac. 2009, 121, 204-212.

53. Kyba, C.; Ruhtz, T.; Lindemann, C.; Fischer, J.; Hölker, F. Two camera system for measurement of urban uplight angular distribution. In Proceedings of the International Radiation Symposium (IRC/IAMAS) Radiation Processes in the Atmosphere and Ocean (IRS2012), Berlin, Germany, 6-10 August 2012; AIP Publishing: Melville, NY, USA, 2013; Volume 1531, pp. 568-571.

54. Ecological Consequences of Artificial Night Lighting; Rich, C., Longcore, T., Eds.; Island Press: Washington, DC, USA, 2006.

55. Hölker, F.; Wolter, C.; Perkin, E.K.; Tockner, K. Light pollution as a biodiversity threat. Trends Ecol. Evol. 2010, 25, 681-682.

56. Organisation for Economic Co-operation and Development (OECD)/International Energy Agency (IEA). Light's Labour's Lost: Policies for Energy-Efficient Lighting; OECD/IEA: Paris, France, 2006.

57. Tsao, J.Y.; Saunders, H.D.; Creighton, J.R.; Coltrin, M.E.; Simmons, J.A. Solid-state lighting: An energy-economics perspective. J. Phys. D Appl. Phys. 2010, doi:10.1088/ 0022-3727/43/35/354001.

58. Riegel, K. Light pollution. Science 1973, 179, 1285-1291.

59. Hölker, F.; Moss, T.; Griefahn, B.; Kloas, W.; Voigt, C.; Henckel, A.; Hänel, A.; Kappeler, P.; Völker, S.; Schwope, A.; et al. The dark side of light-A transdisciplinary research agenda for light pollution policy. Ecol. Soc. 2010, 15, 13. 
60. De Miguel, S.A.; Zamorano, J.; Gómez Castaño, J.; Pascual, S. Evolution of the energy consumed by street lighting in Spain estimated with DMSP-OLS data. J. Quant. Spectrosc. Radiat. Transf. 2014, 139, 109-117.

61. Bennie, J.; Davies, T.W.; Duffy, J.P.; Inger, R.; Gaston, K.J. Contrasting trends in light pollution across Europe based on satellite observed night time lights. Sci. Rep. 2014, doi:10.1038/srep03789.

62. Han, P.; Huang, J.; Li, R.; Wang, L.; Hu, Y.; Wang, J.; Huang, W. Monitoring trends in light pollution in China based on nighttime satellite imagery. Remote Sens. 2014, 6, 5541-5558.

(c) 2014 by the authors; licensee MDPI, Basel, Switzerland. This article is an open access article distributed under the terms and conditions of the Creative Commons Attribution license (http://creativecommons.org/licenses/by/4.0/). 